\title{
Experimental prototype for PWM - Based Sliding Mode Boost Converter
}

\author{
R. A. Abdulhalem \\ University of Hail \\ Faculty of Engineering \\ Haael- KSA \\ abdulhalemra@yahoo.ca
}

Department of Electrical Engineering Department of Electrical Engineer

\author{
Haroutuon A. Hairik \\ University of Basrah \\ College of Engineering \\ Basrah-IRAQ \\ haroutuonhairik@ymail.com
}

\author{
Asmaa J. Kadhem \\ Department of Electrical Engineering \\ University of Basrah \\ College of Engineering \\ Basrah-IRAQ \\ asmaa80 msc@yahoo.com
}

\begin{abstract}
The paper dells with a modified experimental prototype for pulse-width modulation (PWM) sliding mode control (SMC) applied to a DC-to-DC-boost converter operated in continuous conduction mode $(\mathrm{CCM})$. Experimental results show that the proposed control schme provides good voltage regulation and is suitable for common DC-to-DC conversion purposes. The prototype and its implementation are given in detail. The static and dynamic performances of the The static and dynamic performances of the experimental system are recorded. Experimental results show that the proposed control scheme provides good voltage regulation and is suitable for common DC-to-DC conversion purposes.
\end{abstract}

\section{I . INTRODUCTION}

Direct current (DC-to-DC) converters are circuits which convert sources of direct current (DC) from one voltage level to another by changing the duty cycles of the main switches in the circuits [1]. PWM DC-to-DC converters are very popular for the last three decades, and that are widely used at all power levels [2]. Sliding mode control (SMC) gained much popularity in the recent years due to its applicability to nonlinear systems and the ability to consider robustness issues in the global sense. Sliding mode control has been successfully applied to robot manipulators, underwater vehicles, automotive transmissions and engines, high-performance electric motors and power systems [3]. SMC provides a systematic approach to the problem of maintaining stability and consistent performance in the face of modeling imprecision. A boost converter is a power electronic converter with an output DC voltage greater than its input DC voltage; therefore, it is normally used in applications where the output voltage is higher than the source voltage [4]. The control of this type of converters is difficult. The difficulty in the control is due to their non-minimum phase structure, i.e., the control input appears both in the voltage and current equations [5]. The main application of boost converter is in regulated DC power supplies and regenerative of DC motors [6]. The modeling and simulation of the proposed experimental prototype for a fixed-frequency has been presented in [7].

\section{IMPLEMENTATION OF THE PWM - BASED SMVC BOOST CONVERTER}

The experimental implementation of the proposed PWMbased SMVC boost converter goes through the following three stages:

\section{A. Experimental Circuit}

The schematic diagram of the proposed DC-to-DC boost converter circuit is shown in Fig.1.The converter has been designed, and then built and tested in the laboratory. The specifications of the designed converter are given in Table 1. The converter is designed to operate in continuous conduction mode for $\mathrm{V}_{\text {input }}=20 \mathrm{~V}$ to $\mathrm{V}_{\text {input }}=28 \mathrm{~V}$ and $\mathrm{i}_{\text {Load }}=0.2$ to $2 \mathrm{~A}$.

\section{B. Design procedure and the experimental implementation}

The modeling of the proposed experimental prototype and its simulation has been presented in [8]. The design procedure can be summarized as follows: (i) selection of the desired setting time of the response and the type and amount of the required damping; (ii) calculation of the corresponding sliding coefficients using the corresponding sets of equations (1) and (2) [9]:

$W_{N}=\sqrt{\frac{a_{3}}{a_{2}}}$

$\delta=\frac{a_{1}}{2 \sqrt{a_{2} a_{3}}}$

and (iii) inspection of the sliding coefficients appropriateness using the existence conditions and formulation of the control equations by substituting the selected sliding coefficients to calculate for $\mathrm{K}_{\mathrm{p} 1}$ and $\mathrm{K}_{\mathrm{p} 2}$ [10].

The following steps are related to the implementation of the controller of the booster.

\section{Control signal computation}

The computation of the control signal $v_{\text {control }}$ in Eq. (3) can be performed using simple gain amplification and summing functions. 
Table 1: Boost Converter specification

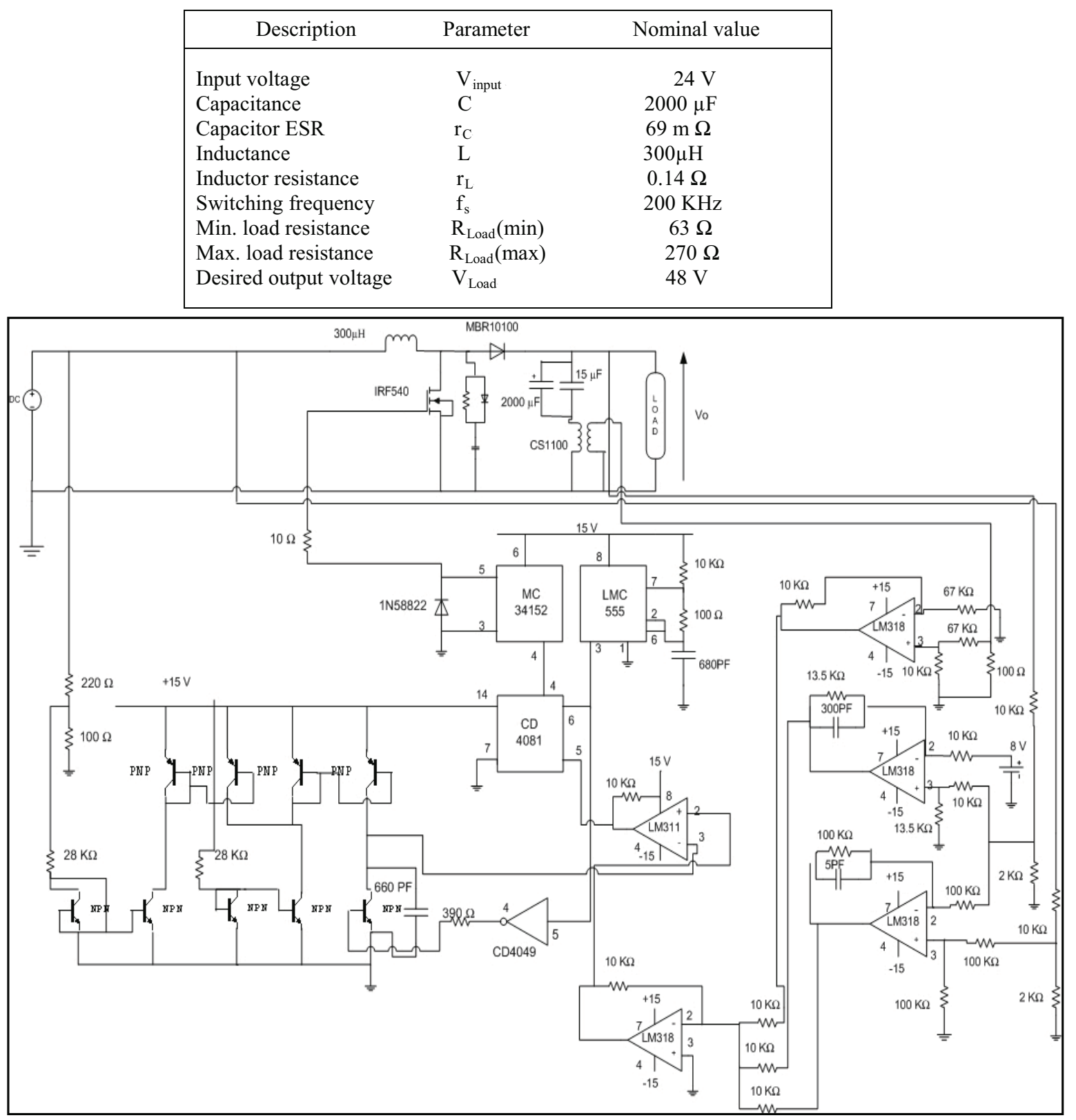

Fig. (1) Schematic diagram of the experimental prototype of DC-DC boost converter.

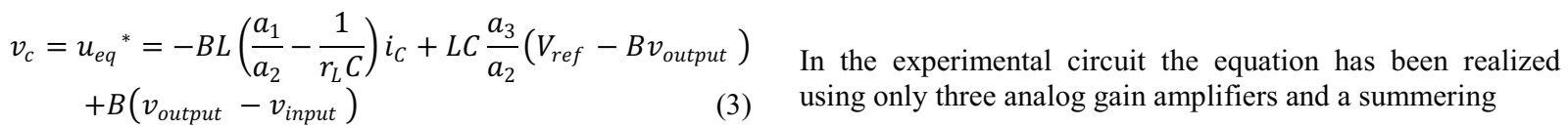


circuit (LM318). The parameters of these circuitries can be easily calculated using known values of $B, \mathrm{r}_{\mathrm{L}}, \mathrm{L}$, and $\mathrm{C}$, and proper choices of $\mathrm{a}_{1}, \mathrm{a}_{2}$, and $\mathrm{a}_{3}$. In the experimental circuit the equation has been realized using only three analog gain amplifiers and a summering circuit (LM318). The parameters of these circuitries can be easily calculated using known values of $B, \mathrm{r}_{\mathrm{L}}, \mathrm{L}$, and $\mathrm{C}$, and proper choices of $\mathrm{a}_{1}$, $\mathrm{a}_{2}$, and $\mathrm{a}_{3}$.

\section{Ramp Signal Generation}

The formulation of the ramp voltage signals $\mathrm{V}_{\text {ramp }}$ for DCto-DC boost converter depends on the instantaneous input and output voltages as shown in Eq. (4).

$V_{\text {ramp }}=B\left(v_{\text {output }}-v_{\text {input }}\right)$

impulse generator using a logic AND IC chip (CD4081). By doing so, the maximum duty cycle of the controller is clamped by the duty cycle of the impulse generator.

\section{Duty Cycle Protection}

The incorporation of the control and ramp signal circuitries into the pulse-width modulator (LM311) forms the basic architecture of the PWM-based SM controller. However, recalling that the boost type converter cannot operate with a switching signal $\mathrm{u}$ that has a duty cycle $\mathrm{d}=1$, a small protective circuit is required to ensure that the duty cycle of the controller's output is always $\mathrm{d}<1$. In our experimental circuit, that is satisfied by multiplying the logic state $u_{P W M}$ of the pulse-width modulator with the logic state $\mathrm{u}_{\mathrm{CLK}}$ of the impulse generator using a logic AND IC chip (CD4081). By doing so, the maximum duty cycle of the controller is clamped by the duty cycle of the impulse generator.

\section{4) Switching Frequency Selection}

The adoption of fixed frequency transforms the SM controller into a type of quasi sliding-mode controller, which operates as an approximation of the ideal SM controller. The consequence of this transformation is the reduction of the system's robustness and the deterioration of the regulation properties. Similar to all other types of controller, the performance of this controller improves with a higher switching frequency. Likewise, the selection of the switching frequency should be a balance between control performance and the converter's specifications.

\section{Special Components Used In the Experimental Circuit}

\section{Current Sensor CS1100}

This current sensor is operated as a secondary of a current transformer. The conductor carrying the current to be measured is the "one turn primary". Sensitivity can be set at 1 Volt per Ampere or at any other desired values. Applications include sensing branch circuit overload, switcher feedback, and detecting load drop or shutdown.

The sensor in our experimental circuit is used to sense the capacitor current and fed it to the controller. The specifications of the sensor are as shown in Table 2:
Table 2: Current Sensor CS1100 specifications

\begin{tabular}{|c|c|c|c|c|}
\hline Turns & $\begin{array}{l}\text { Sensed } \\
\text { Current } \\
\operatorname{Max}(\mathrm{A})\end{array}$ & $\begin{array}{l}\text { Sensiti } \\
\text { Vo(V) }\end{array}$ & $\mathrm{I}_{\mathrm{i}}(\mathrm{A})$ & $\begin{array}{l}\text { Terminal } \\
\text { Resistor } \\
\mathrm{R}_{\mathrm{T}}(\mathrm{Ohm})\end{array}$ \\
\hline 100 & 24 & 1 & 1 & 100 \\
\hline
\end{tabular}

\section{High Speed Dual MOSFET Driver}

The MC34152 is dual non inverting high speed driver specifically designed for applications that require low current digital signals to drive large capacitive loads with high slew rates. This device feature low input current making it CMOS/LSTTL logic compatible, input hysteresis for fast output switching that is independent of input transition time, and two high current totem pole outputs ideally suited for driving power MOSFETs. Also included an under voltage lockout with hysteresis to prevent system erratic operation at low supply voltage.

Its typical applications include switching power supplies, DC-DC converters, capacitor charge pump voltage doublers/inverters, and motor controllers.

\section{LMC555 CMOS Timer}

The LMC555 is a CMOS version of the industry standard 555 series general purpose timers. The LMC555 offers the same capability of generating accurate time delays and frequencies as the LM555 but with much lower power dissipation and supply current spikes. When operates as a one-shot, the time delay is precisely controlled by a single external resistor and capacitor. In the stable mode, the oscillation frequency and duty cycle are accurately set by two external resistors and one capacitor. The use of National Semiconductor's LMCMOS ${ }^{\mathrm{TM}}$ process extends both the frequency range and low supply capability. 


\section{Experimental Results}

The derived controller is verified through an experimental circuit developed with the specifications shown in Table 1. The theoretical description of the signals is derived and shown in Table 3.

The experimental circuits are tested for the following steady and dynamic conditions:

1. Load step change from 270 to 63 then to 270 for 24 Volt, shown in Figs. 2 and 3.

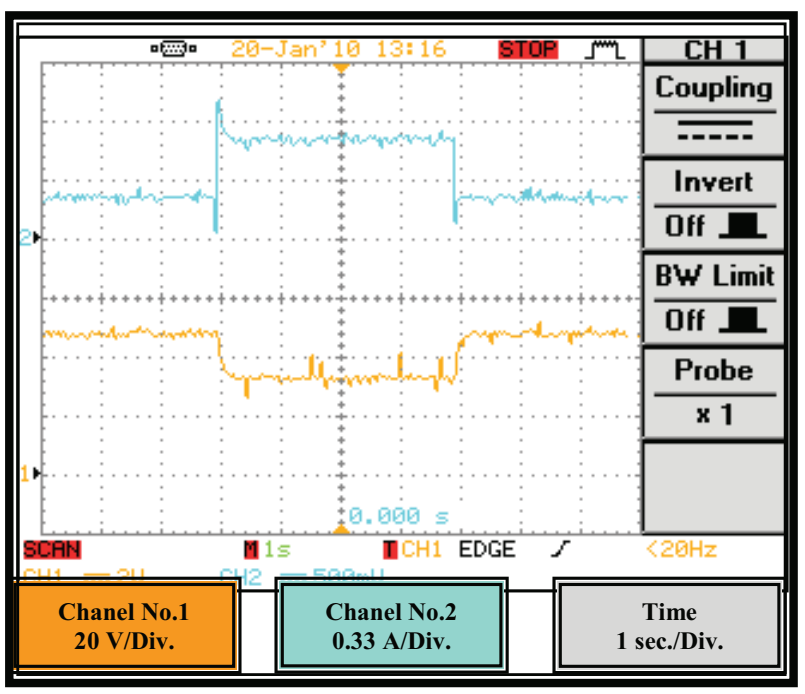

Figure 2: Chanel (1): Output voltage profile during load step change instants. , when $V_{\text {in }}=24$ volt

Chanel (2): Load current profile at load step change instants, when $V_{\text {in }}=24$ volt (open loop condition)

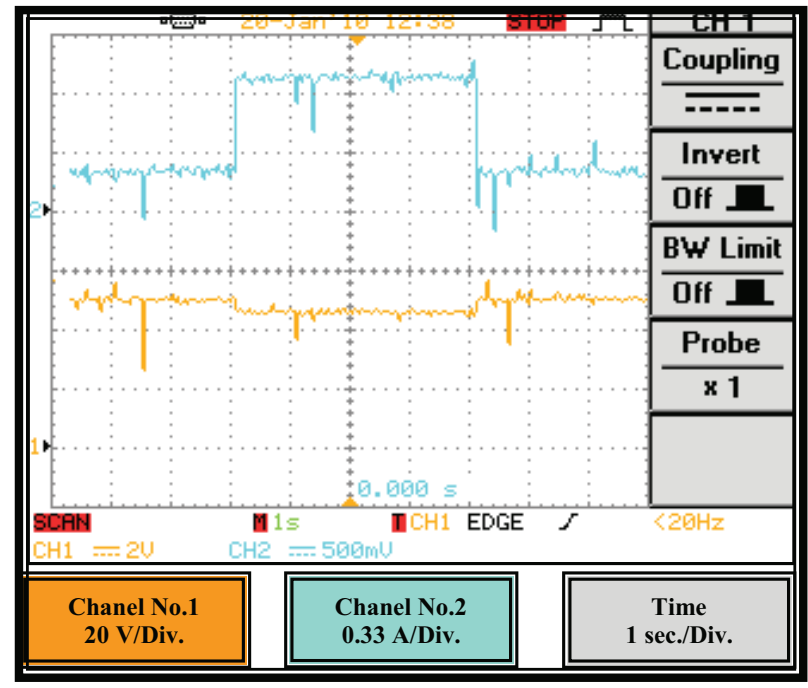

Figure 3: Chanel (1): Output voltage profile at load step change instants, when $V_{\text {in }}=24$ volt Chanel (2): Load current profile at load step change instants, when $V_{\text {in }}=24$ volt

Figure 2 shows the experimental waveform of output voltage without controller at load step change from 270 to 63 $\Omega$ at $\mathrm{t}=3 \mathrm{sec}$, then from 63 to $270 \Omega$ at $\mathrm{t}=7 \mathrm{sec}$, we note that the voltage deviation is about ( 8 volt), Fig. 3 channel (1) shows experimental waveform of the output voltage with a controller, the voltage deviation is (2 volt). The load current variation during load step change instants is shown in Fig. 3 channel (2).

Figure 4 channel (1) shows experimental waveform of the output voltage at switching on instant of the converter at $R_{L}=270 \Omega, V_{\text {in }}=24$ volt at $t=5 \mathrm{sec}$, the load current is shown in channel (2). The capacitor current, the voltage across the inductor and the input current at the same operating condition are shown in Figs. 5, 6 and 7 respectively 


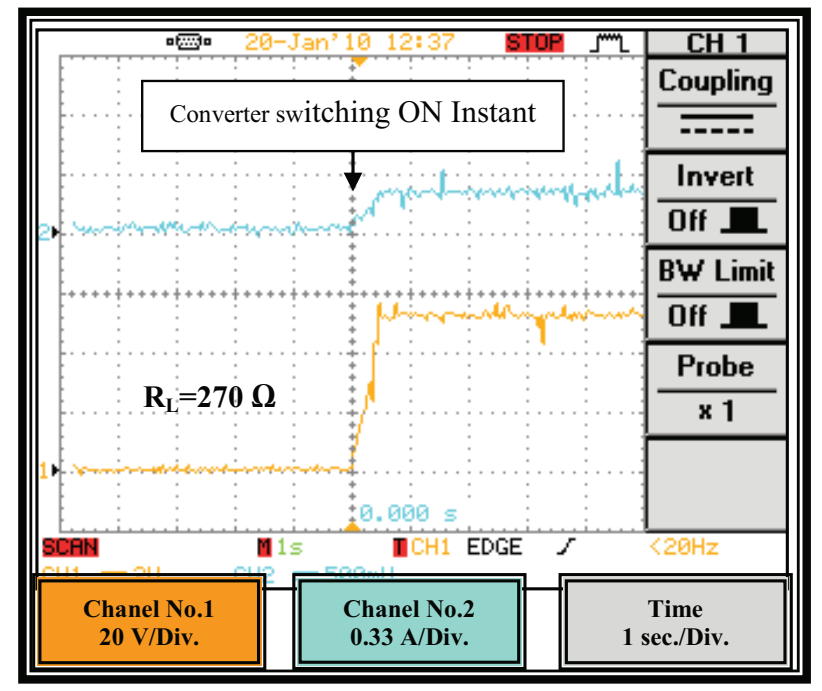

Figure 4: Chanel (1): Output voltage profile at switching $O N$ instant, when

$$
R_{L}=270 \Omega, V_{\text {in }}=24 \text { volt }
$$

Chanel (2): Load current profile at

switching ON instant, when $V_{\text {in }}=24$ volt

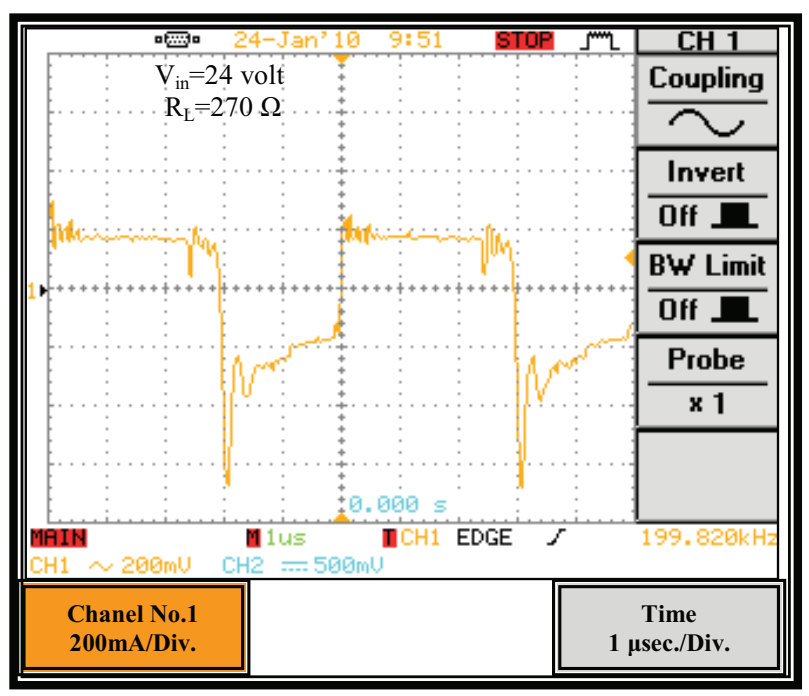

Figure 5: Capacitor current waveform.

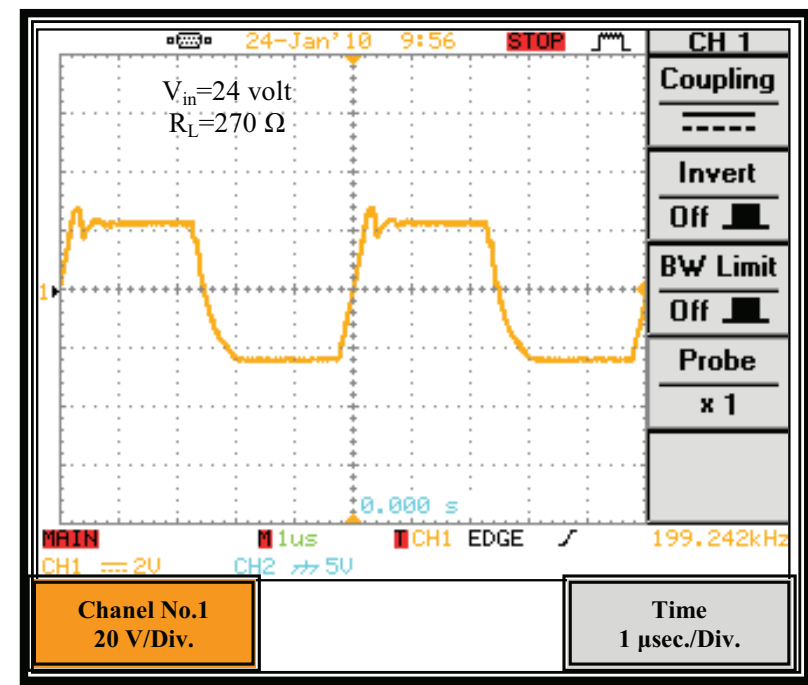

Figure 6: Inductor voltage waveform.

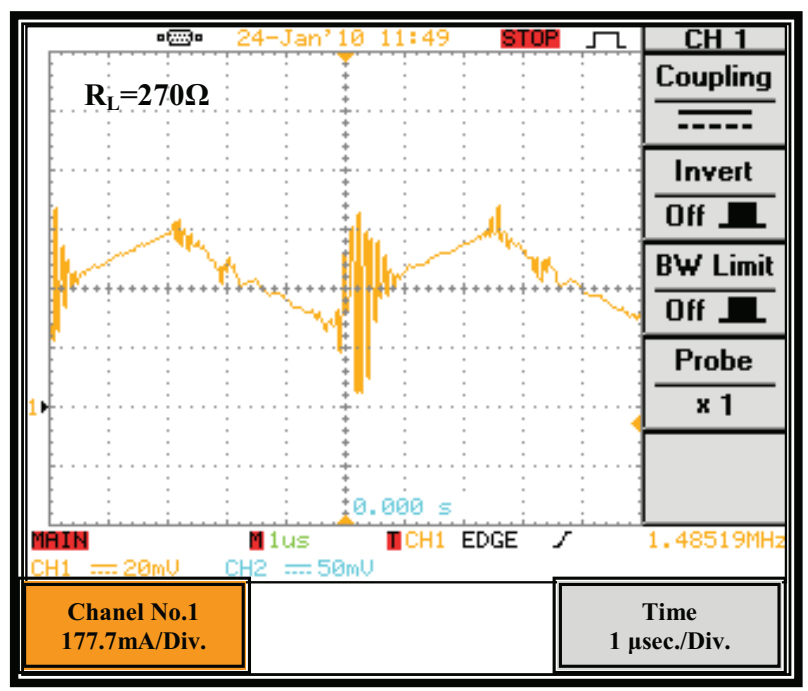

Figure 7: Input current waveform for the continuous mode of operation 
2. Line variation (input voltage step change) from 24 to 28 then to 24 Volt at load $270 \Omega$, shown in Figs. 8 and 9.

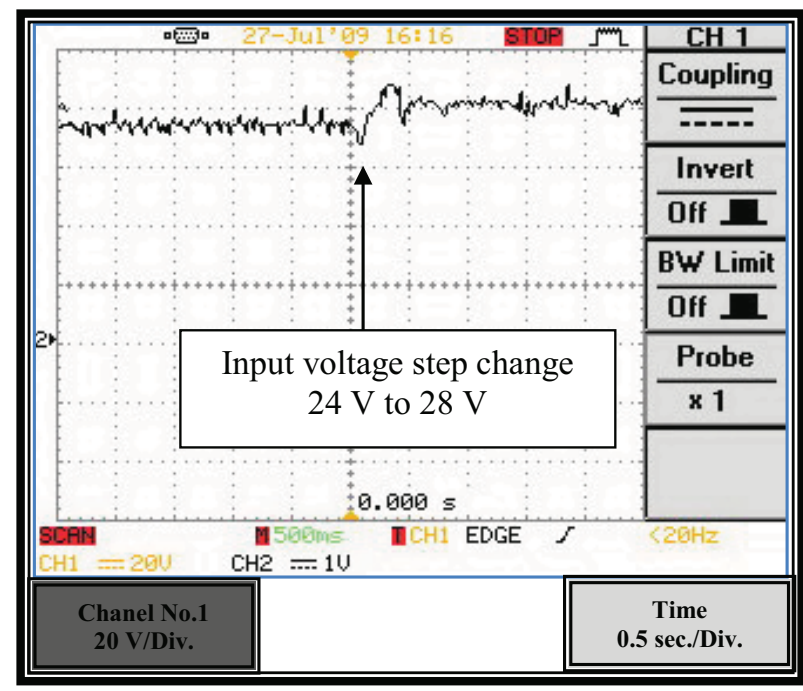

Figure 8: Output voltage profile during input voltage step change 24 to 28 volt. (Open loop condition)

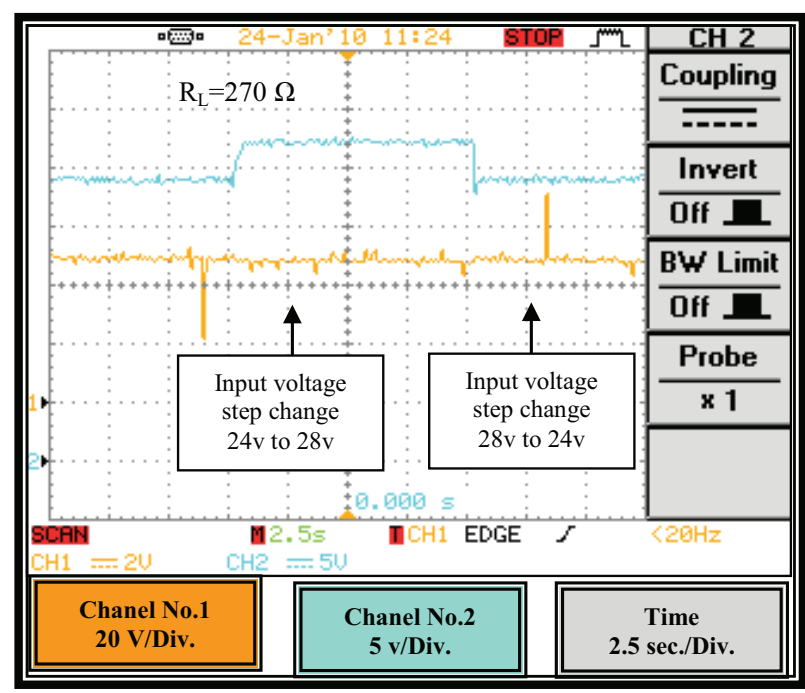

Figure 9: Output voltage waveform during input voltage step changes

Two step changes in the input voltages from 24 to 28 volt then from 28 to 24 volt
3. Line variation (input voltage step change) from 20 to 28 then 20 Volt at load $(270 \Omega)$, is shown in Fig. 10.

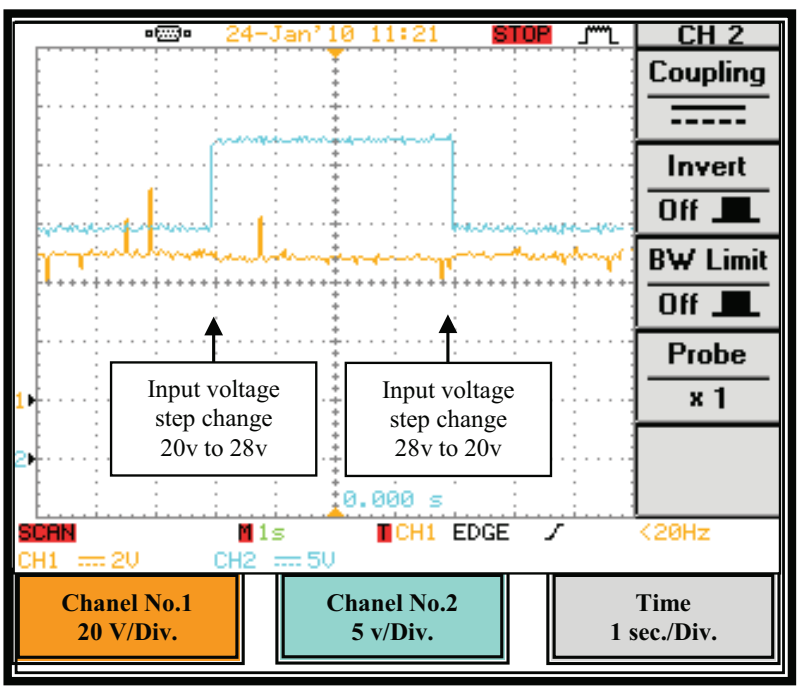

Figure 10: Output voltage waveform during input voltage step changes Two step changes in the input voltages from 20 to 28 volt then from 28 to 20 volt

The PWM-based SMVC boost converter, which is designed and tested for operation in CCM, is also tested in discontinuous conduction mode (DCM) at 24 volt input voltage and load $3.5 \mathrm{k} \Omega$, the result is shown in Fig. 11 .

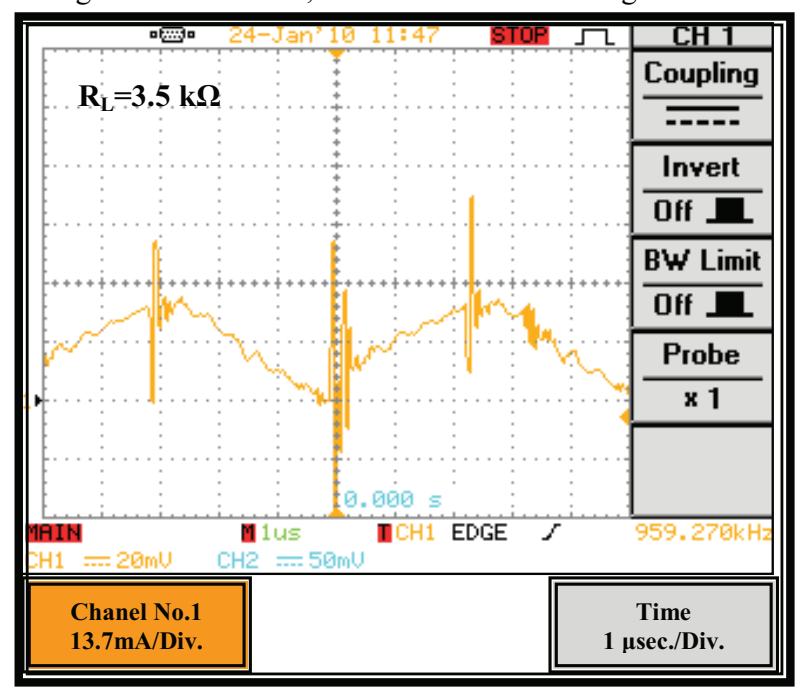

Figure 11: Input current waveform for the discontinuous conduction mode operation 


\section{Conclusions}

In this paper, PWM- based sliding mode voltage controller for DC-to-DC boost converter has been designed and implemented. The PID control was implemented in the boost converter using prototype model. The circuit was tested in steady state and under different dynamic variations. The prototype gave excellent results under different conditions. So, it can be said that the SMC design for DC-to-DC converters allows a high-performance control system.

\section{References}

[1] Hong Li, Zhong Li, Bo Zhang, Wallace K.S Tang, and Wolfgang A. Halang, "Suppressing Electromagnetic interference in direct current converters" IEEE Circuits and Systems Magazine, Vol.9, No.4 Fourth Quarter 2009, PP.10-26.

[2] Muhammad H. Rashid, "Power electronics handbook", Academic Press 2001, ISBN 0-12581650-2.

[3] P. Mattavelli, L.Rossetto, G. Spiazzi, and P. Tenti, " General-purpose sliding-mode controller for DC/DC converter applications", Proceeding of the IEEE Power Electronics Specialists Conference, (PESC 93) Records, 20-24 June 1993 pp.609-615.

[4] K. Marian K. Kazimierczuk, "Pulse-width modulated dc-dc power converters", John Wiley and Sons, Ltd, Publication, first edition 2008, ISBN 978-0-47077301-7.

[5] Hanifi Guldemir, "Sliding mode control of DC-DC boost converter", Asian Network for Scientific Information 2005, ISSN 1812-5654, PP.588-592.

[6] N. Mohan, T. Undeland, W. Robbins, "Power Electronics, Converters, Applications and design", 3rd Edition, John Wiley \&Sons, INC,2003, ISBN 0-47122693-9 USA.

[7] Ramzi AhmedAbdulhalem, Haroutoun A. Hairik, Hisham L. Swady, and Asmaa J. Kadhem, "Modeling and Simulation of PWM sliding Mode Voltage Controller for DC/DC Boost Converters Operating in Continuous Conduction Mode ", The 10th international Conference on Sciences and Techniques of Automatic control \&computer engineering STA, December 20-22, 2009, Hammamet, Tunisia.

[8] Siew Chong Tan, Y.M Lai, and Chi K. Tse, "Implementation of pulse -width-modulation based sliding mode controller for boost converters", IEEE Power Electronic Letters, Vol.3, No.4, December 2006, PP.130-135.

[9] Siew Chong Tan, Y.M Lai, Chi K. Tse, and Martin K.H. Cheung, "A pulse -width - modulation based sliding mode controller for buck converters", IEEE Power Electronics Specialists Conference, 2004, PP.3647-3653.

\section{Appendix}

Experimental setup of PWM-based SMVC boost converter

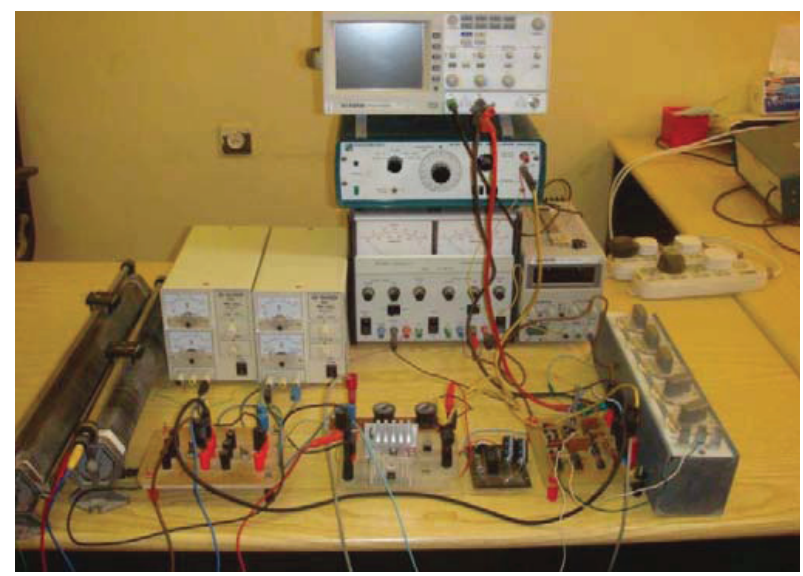

